\title{
Patient-reported impacts of a conservative management programme for the clinically inapparent adrenal mass
}

\author{
Andreas Muth · Charles Taft • Lilian Hammarstedt • \\ Lena Björneld • Mikael Hellström • \\ Bo Wängberg
}

Received: 6 September 2012/Accepted: 4 December 2012/Published online: 20 December 2012

(C) The Author(s) 2012. This article is published with open access at Springerlink.com

\begin{abstract}
The aim of this study was to assess patientreported impacts and health-related quality of life (HRQL) of a 2-year follow-up programme in a large cohort of patients with stationary, non-functioning, adrenal incidentalomas (AIs) in western Sweden. 145 patients (mean age 68 years, $62 \%$ females) with AI from a prospective study in western Sweden were studied. All had completed a 2-year follow-up programme by November 2007, without evidence of adrenal malignancy or hormone over-production. To evaluate patient-reported impacts and HRQL, an eight-item adrenal incidentaloma impact questionnaire was used retrospectively, together with the hospital anxiety and depression scale, and the short form-36. There were 111 patients (mean age 67 years, $63 \%$ females) who responded to the questionnaire (response rate $77 \%$ ). $77 \%$ reported that the AI diagnosis had caused them to be worried; however, fewer than $20 \%$ had thought about the lesion often during the follow-up programme, and only $3 \%$ had felt that it had a
\end{abstract}

A preliminary version of this work was presented (oral presentation) at the American Association of Endocrine Surgeons 30th Annual Meeting, Madison, Wisconsin 2009.

A. Muth $(\square) \cdot$ B. Wängberg

Department of Surgery, Sahlgrenska University Hospital,

Sahlgrenska Academy, University of Gothenburg, SE-413 45

Gothenburg, Sweden

e-mail: andreas.muth@vgregion.se

C. Taft

Institute of Health and Care Sciences, University of Gothenburg

Centre for Person-Centred Care, Sahlgrenska Academy,

University of Gothenburg, Gothenburg, Sweden

L. Hammarstedt · L. Björneld · M. Hellström

Department of Radiology, Sahlgrenska Academy, University

of Gothenburg, Gothenburg, Sweden large impact on their current daily life. Only $4 \%$ stated that the follow-up programme had been a negative experience, nevertheless $10 \%$ reported a negative impact on their HRQL during the follow-up programme. Only $2 \%$ stated that release from follow-up caused worry to any degree. In total, $29 \%$ had possible anxiety, and $30 \%$ had possible depression, probably reflecting significant co-morbidity. Possible anxiety correlated with a more negative experience of the follow-up programme. In conclusion, the 2-year follow-up programme for patients with AI was well tolerated. Nonetheless, a small number remained worried throughout follow-up, suggesting the need for tailored counselling in individual patients to ameliorate negative impacts of follow-up.

Keywords Adrenal gland neoplasm - Incidental findings · Computed tomography · Quality of life · Follow-up · Adult

\section{Introduction}

The purpose of follow-up for patients with incidentally discovered adrenal lesions (also known as adrenal incidentalomas (AIs)) is to identify individuals with malignant or hormone-producing tumours. However, the majority of patients with AIs have benign, non-functioning adenomas that can be managed conservatively [1-6]. Management of patients with AI imposes a significant burden on health-care providers, as adrenal lesions are frequent findings on abdominal computed tomography (CT) and magnetic resonance imaging performed for unrelated reasons. In a survey in western Sweden, AIs were seen in 4.5\% (range 1.8-7.1\% between hospitals) of abdominal CT scans [7]. In autopsy studies, the prevalence of adrenal tumours approaches $7 \%$ in patients over 70 years of age [8]; hence, as advanced 
cross-sectional imaging is increasingly performed in the elderly population the detection of AIs can be expected to rise.

Concerns about hormone-production or malignancy developing in the $\mathrm{AI}$ over time provide the rationale for follow-up programmes, but the extent of follow-up is debated [9, 10]. In 2002, the U. S. National Institute of Health published a state-of-the science report on the incidentally discovered adrenal mass, identifying areas of interest for future studies [11]. The impact of being diagnosed with an $\mathrm{AI}$ and subsequent follow-up on healthrelated quality of life (HRQL) was highlighted as a priority area. To date, little research has addressed this issue.

We assessed patient-reported impact of a 2-year followup programme and HRQL in a large cohort of patients with stationary, non-functioning AIs in western Sweden.

\section{Patients and methods}

The prospective cohort study of AI in western Sweden

During an 18-month period, all patients with AIs identified at all radiology departments in western Sweden (serving inand out-patient care for 1.7 million inhabitants,) were prospectively reported and enrolled in a 2-year follow-up programme. The programme has previously been described in detail $[6,7]$. At detection, the patients were informed about the study by their attending physician, and referred for evaluation to one of the local study coordinators (consultants in internal medicine, endocrinology or endocrine surgery) at the Sahlgrenska University Hospital, or one of the six county hospitals in the region. All patients received oral and written information about the study and gave written consent. key points in the written information were that: a lesion in the adrenal had been incidentally found; adrenal lesions in most cases are benign and require no specific treatment, although some represent 'tumours' that may require surgery or special medication; the purpose of follow-up was to detect hormone-producing lesions or lesions suspicious for malignancy; the follow-up programme in the study was compliant with national guidelines; and if no signs of hormone production or malignancy were seen after 2 years, then no further follow-up was necessary. Additional individualized information was provided as found necessary.

The follow-up programme

Dedicated adrenal CT was scheduled at 4, 12 and 24 months as previously described [6]. Clinical and biochemical evaluation was scheduled at baseline and after 24 months. Adrenomedullary function was assessed with $24 \mathrm{~h}$ urinary catecholamines and/or metanephrines. Adrenocortical function was assessed using 24-h urinary-free cortisol (UFC) and aldosterone (in hypertensive patients, measurements were taken once again); plasma aldosterone and upright renin were assessed; and a 1-mg dexamethasone suppression test ( $1 \mathrm{mg}$-DST) was performed. After 24 months, baseline biochemical work-up was repeated, and all patients underwent $1 \mathrm{mg}$-DST. Suppression $<60 \mathrm{nmol} / \mathrm{L}$ [12] was regarded as normal, while values $>138 \mathrm{nmol} / \mathrm{L}$ [13] were regarded as insufficient. In patients with $1 \mathrm{mg}$-DST cortisol levels in the range of $60-138 \mathrm{nmol} / \mathrm{L}$, other factors such as age and co-morbidities were taken into account. Patients with insufficient suppression at $1 \mathrm{mg}$-DST were scheduled for further examinations, including measurement of ACTH, long-term suppression tests and repeat UFC.

Criteria for conservative management

Criteria for conservative management were radiologically stationary lesions with benign features [14], and no evidence of hormone over-production (including subclinical hypercortisolism). Follow-up was terminated after 24 months in patients who fulfilled these criteria, and these patients were eligible for inclusion in the present study. Adrenalectomy was considered for patients with unilateral tumours $>3 \mathrm{~cm}$ in transaxial diameter, tumours with interval growth, or tumours with other features suspicious for malignancy [14] and/or hormone over-production. Some patients with tumours $>3 \mathrm{~cm}$ were managed conservatively because of benign radiological characteristics, severe comorbidity, or patient preferences.

\section{Study population}

One hundred and forty-five patients (mean age 68 years, $62 \%$ females), who fulfilled the criteria for conservative management and had completed the 2-year follow-up programme by November 2007, constituted the study population. Information on results of biochemical evaluations (UFC and $1 \mathrm{mg}$-DST cortisol levels), patient's height and weight, the presence of diabetes, hypertension, other cardiovascular disease, and previous history of malignancy was retrieved from the main study database. Diagnoses of malignancy were crosschecked against the Swedish National Cancer Register (http://www.socialstyrelsen.se/ register/halsodataregister/cancerregistret/inenglish).

Development of an adrenal incidentaloma impact questionnaire (AIIQ)

In order to gain insight into the patients' experiences of the follow-up programme, interviews were conducted by one of the authors (BW) with two randomly selected patients who had been managed conservatively for AI. Analysis of 
the interview material yielded a dominating theme of worry-relief. On the basis of these interviews, an 8-item questionnaire was developed with questions regarding specific points of interest during the follow-up programme. Items were constructed to assess: (A) worry, preoccupation and psychological impact of the diagnosis and follow-up of the AI, and (B) appraisals of the follow-up programme as such. Items were framed to cover: (1) the time of diagnosis, (2) the follow-up period, (3) the time at completion of the programme, and (4) the time after finishing the programme. A panel of physicians with experience in treating AI patients reviewed the items, and the questionnaire was assessed for face validity (comprehensibility, relevance and comprehensiveness) by senior nurses at the endocrine unit.

Rationale for using additional instruments

We assumed that the follow-up programme for AI would affect the patients' HRQL principally in the area of psychological well-being and mental health, rather than physical functioning. The Swedish version of the generic short form-36 (SF-36) [15] was used to assess HRQL. The SF-36 is a 36-item survey that measures eight domains of health: physical functioning, role limitations due to physical health, bodily pain, general health perceptions, vitality, social functioning, role limitations due to emotional problems, and mental health. An age- and sex-matched reference group $(n=145)$ was randomly drawn from the Swedish normative database [15]. To evaluate anxiety and depression, we used the hospital anxiety and depression scale (HADS) [16]. The HADS consists of two subscales evaluating anxiety (HADS-A, 7 items) and depression (HADS-D, 7 items). We used established and validated cutoff values $(<8$ non-cases, $8-10$ possible cases, and $>10$ probable cases) for each scale that were proposed by the developers. Using the cut-off $\geq 8$, the sensitivity and specificity for detecting anxiety or depression are both approximately 0.8 [17].

\section{Administration of questionnaires}

The three questionnaires, accompanied by a letter signed by the two principal investigators of the clinical follow-up study and a stamped return envelope addressed to an independent institute, were sent by mail on the 15th of November 2007. Two reminders were used. The second reminder included a new copy of the questionnaire and patients who declined to participate were asked to endorse a reason for not responding. Response alternatives were: To my knowledge I have not participated in such a programme; I think the questionnaire is too long; I haven't time; I don't understand the questions; I don't see the purpose of the questionnaire; I see no point in answering the questionnaire;
I don't think the questions are about me; I think the questions are too intimate; I don't feel strong enough to answer the questions; Other reason, please state:....

\section{Statistical analysis}

Frequencies were computed for each of the AIIQ items. Response alternatives were coded from 1 to 5 , where higher values indicate more positive responses. Inter-item correlations were calculated using Spearman's rho $\left(r_{\mathrm{s}}\right)$. An exploratory factor analysis using Varimax rotation was performed. The Kaiser rule for factor extraction was applied. Summated scores of the items comprising the factors were correlated $\left(r_{\mathrm{s}}\right)$ with the scores on the HADS and the SF-36.

Correlations between patient characteristics (age, sex and co-morbidities), tumour characteristics (tumour size and location (uni- or bilateral), UFC and $1 \mathrm{mg}$-DST cortisol levels), and HRQL were performed using Spearman's rho. To assess the impact of co-morbidities, a crude comorbidity index was used awarding one point each for hypertension, other cardiovascular disease (e.g. congestive heart failure and paroxysmal atrial fibrillation), diabetes and previous or concurrent of extra-adrenal malignancy, yielding a score from 0 to 4 .

Analysis of AIIQ items across different participating clinical units, and comparisons between AIIQ items and HADS (non-cases, possible cases and probable cases) were performed using the Kruskal-Wallis test followed by the Mann-Whitney $U$ test.

Further comparisons between HADS non-cases, possible and probable cases, and UFC- and $1 \mathrm{mg}$-DST cortisol levels were performed using one-way analysis of variance (ANOVA), and, for $1 \mathrm{mg}$-DST, the Chi-square test using serum cortisol cut-off levels of 50 [18], 60 [12], 83 [19] and 138 [13] nmol/L. SF-36 data from respondents, and matched controls was analysed using the Mann-Whitney $U$ test. Calculations were performed using IBM SPSS Statistics version 19 (IBM Corporation, Somers, NY).

\section{Results}

Patient characteristics and response rate

In total, 111 patients (mean age 67 years; $63 \%$ females) responded (response rate $77 \%$ ). Data were complete for the AIIQ in 110 cases (109 in items 3 and 8), HADSanxiety (HADS-A) in 108 cases, HADS-D in 109 cases and SF-36 in 108 cases. For characteristics of responders and non-responders, see Table 1 . In 15 of 34 cases, a reason for not responding was stated: Old age/Questionnaire too demanding $n=6$; Questionnaire not relevant $n=3$; 
Table 1 Characteristics of patients responding and not responding to the questionnaires

\begin{tabular}{|c|c|c|}
\hline & Responders & Non-responders \\
\hline Subjects, $n(\%)$ & $111(100)$ & $34(100)$ \\
\hline $\begin{array}{l}\text { Age in years, mean } \\
\text { (median, range) }\end{array}$ & $67(67,30-90)$ & $70(74,27-89)$ \\
\hline Females, $n(\%)$ & $70(63)$ & $20(59)$ \\
\hline $\begin{array}{l}\text { Bilateral lesions, } \\
n(\%)\end{array}$ & $23(21)$ & $9(26)$ \\
\hline $\begin{array}{c}\text { Size in mm, mean } \\
\text { (median, range) }\end{array}$ & $24(23,12-91)$ & $26(22,15-54)$ \\
\hline $\begin{array}{l}\text { UFC at completion, } \\
\text { mean } \pm 2 \mathrm{SD} \\
(\text { ref. } 75-350 \mathrm{nmol} / \\
24 \mathrm{~h})\end{array}$ & $168.8 \pm 201.3$ & $180.7 \pm 143.1$ \\
\hline $\begin{array}{l}1 \mathrm{mg} \text {-DST cortisol } \\
\text { levels at completion, } \\
\text { mean } \pm 2 \mathrm{SD} \\
(\mathrm{nmol} / \mathrm{L})\end{array}$ & $54.7 \pm 63.8$ & $49.6 \pm 43.4$ \\
\hline \multicolumn{3}{|l|}{$\begin{array}{l}\text { Diagnosis at detection*, } \\
n(\%)\end{array}$} \\
\hline B Infection & $1(1)$ & $0(0)$ \\
\hline $\begin{array}{l}\text { C Malignant } \\
\text { neoplasm }\end{array}$ & $20(18)$ & $2(6)$ \\
\hline $\begin{array}{l}\text { D 00-48 Benign } \\
\text { neoplasm }\end{array}$ & $3(3)$ & $1(3)$ \\
\hline D 50-89 Blood & $1(1)$ & $0(0)$ \\
\hline E Endocrine & $1(1)$ & $0(0)$ \\
\hline F Mental/behavioural & $0(0)$ & $1(3)$ \\
\hline I Circulatory & $11(10)$ & $1(3)$ \\
\hline J Respiratory & $4(4)$ & $2(6)$ \\
\hline K Digestive & $36(32)$ & $11(32)$ \\
\hline M Musculoskeletal & $8(7)$ & $0(0)$ \\
\hline N Genitourinary & $2(2)$ & $2(6)$ \\
\hline R Symptoms & $16(14)$ & $5(15)$ \\
\hline S Trauma & $2(2)$ & $4(12)$ \\
\hline Y External causes & $2(2)$ & $0(0)$ \\
\hline $\begin{array}{l}\text { Z Control after } \\
\text { therapy }\end{array}$ & $4(4)$ & $5(15)$ \\
\hline \multicolumn{3}{|c|}{ Co-existing conditions, $n(\%)$} \\
\hline Hypertension & $53(48)$ & $13(38)$ \\
\hline $\begin{array}{c}\text { Cardiovascular } \\
\text { disease }^{\dagger}\end{array}$ & $25(23)$ & $6(18)$ \\
\hline Diabetes mellitus & $10(9)$ & $10(29)$ \\
\hline Hyperlipidemia & $13(12)$ & $1(3)$ \\
\hline Osteoporosis & $5(5)$ & $3(9)$ \\
\hline BMI $\left(\mathrm{kg} / \mathrm{m}^{2}\right)>25^{\ddagger}$ & $45(41)$ & $7(21)$ \\
\hline $\begin{array}{l}\text { History of } \\
\text { malignancy }\end{array}$ & $18(16)$ & $6(18)$ \\
\hline
\end{tabular}

$\overline{U F C \text { urinary free cortisol, } 1 \mathrm{mg} \text {-DST } 1 \mathrm{mg} \text { overnight dexametasone suppression }}$ test

* Results of the work-up for the complaints that led to the incidental discovery of adrenal lesions, grouped according to the International Classification of Diseases, version 10 (ICD-10), ${ }^{\dagger}$ Other than hypertension (ICD-10 code I 10.9), ${ }^{\ddagger}$ BMI data missing on 25 responders and 15 non-responders

Dementia $n=2$; No recollection of having participated in a follow-up programme $n=2$; Language problems $n=1$; Matter of principle $n=1$. In 19 cases, no explanation was offered.
Responses to the AIIQ and factor analysis

Responses to the AIIQ are summarized in Fig. 1a, b. Exploratory factor analysis supported a two-factor model (eigenvalue $>1$ ) explaining $61 \%$ of the variance (Table 2 ). AIIQ-items 1, 2, 4 and 5 formed the first factor, labelled preoccupation with the $\mathrm{AI}$, while the second factor comprised items 3 and 6-8, and was labelled evaluation of the programme as such.

\section{Preoccupation with the AI}

The AI diagnosis caused some worry in $85 / 110$ patients (77 \%, item 1, Fig. 1a). During follow-up 20/110 (18\%) thought about the lesion often (item 2). However, after the follow-up programme only $3 / 110$ (3\%) patients reported significant impacts on their everyday life (item 4), and $15 / 110(14 \%)$ thought about the lesion sometimes, while $3 / 110(3 \%)$ thought about it often, or all the time (item 5).

\section{Evaluation of the programme}

Only 2/109 (2\%) reported that the termination of follow-up had made them feel more worried (item 3, Fig. 1b). In total, $11 / 110(10 \%)$ reported that their HRQL had been negatively impacted during the follow-up programme (item 6); however, only 4/110 (4\%) reported that they had experienced the programme as negative (item 7). The majority of patients were satisfied with the information received, but $21 / 109(19 \%)$ felt that the information about the adrenal lesion had been insufficient or very insufficient (item 8).

\section{Assessment of information}

The patients' assessment of the information given (item 8) correlated with the reaction at termination of the programme (item 3: $r_{\mathrm{s}}=0.33, p=0.001$ ), impact on everyday life (item 4: $r_{\mathrm{s}}=0.22, p=0.02$ ), preoccupation during last month (item 5: $r_{\mathrm{s}}=0.29, p=0.002$ ), and overall assessment of the programme afterwards (item 7: $r_{\mathrm{s}}=0.30$, $p=0.002$ ). No differences in the patients' assessments were seen between the participating clinical units.

Responses to the hospital anxiety and depression scale and SF-36

In total, 12 respondents $(11 \%)$ scored as possible cases and $19(18 \%)$ as probable cases according to HADS-A. Sixteen $(15 \%)$ scored as possible cases and $16(15 \%)$ as probable cases according to HADS-D. There was considerable overlap in cases of anxiety and depression with 21 respondents scoring as possible or probable cases of both anxiety and depression. 


\section{A-Preoccupation}

Item 1: When I was informed that I

Item 2: During the follow-up period I thought about the adrenal mass had an adrenal mass / became

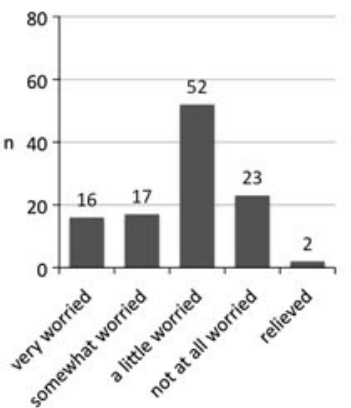

Item 4: Knowing that I have an adrenal mass has affected my quality of life

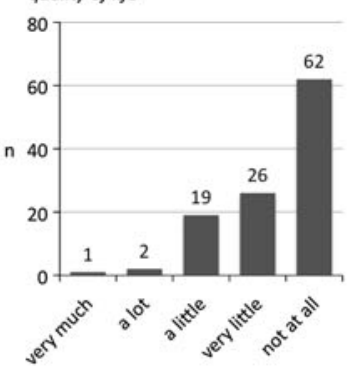

Item 5: During the past month I have thought about the adrenal mass

4 Fig. 1 The adrenal incidentaloma impact questionnaire, distribution of responses for each item. Items grouped according to the factor analysis. a Preoccupation with the adrenal incidentaloma. b Evaluation of the follow-up programme

Respondents scored significantly lower than norms on all SF-36 domains, except bodily pain (Fig. 2). This finding was exclusively accounted for by respondents with one, or several co-morbidities (previous or concurrent extra-adrenal malignancy, cardiovascular disease or diabetes).

\section{Relationships between the AIIQ, HADS and SF-36}

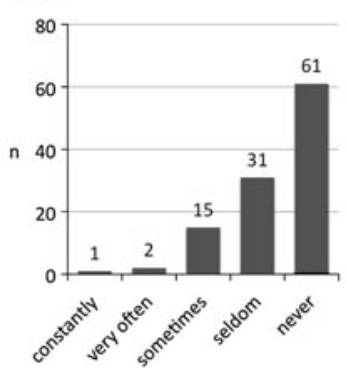

\section{B-Evaluation}

Item 3: When I was informed that the adrenal mass was not dangerous and that further follow. up was unnecessary l felt

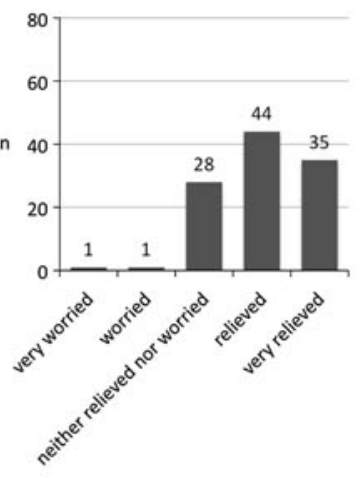

Item 6: During follow-up / felt that the tests and $x$-rays affected my quality of life
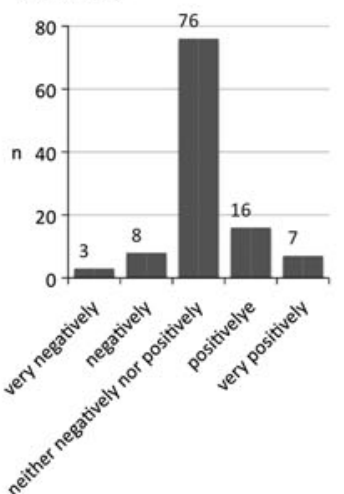

\section{Item 7: Today I feel that having} gone through these careful medical examinations was

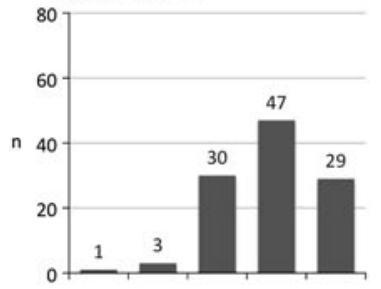

Item 8: On the whole, the information I recieved about the adrenal mass was
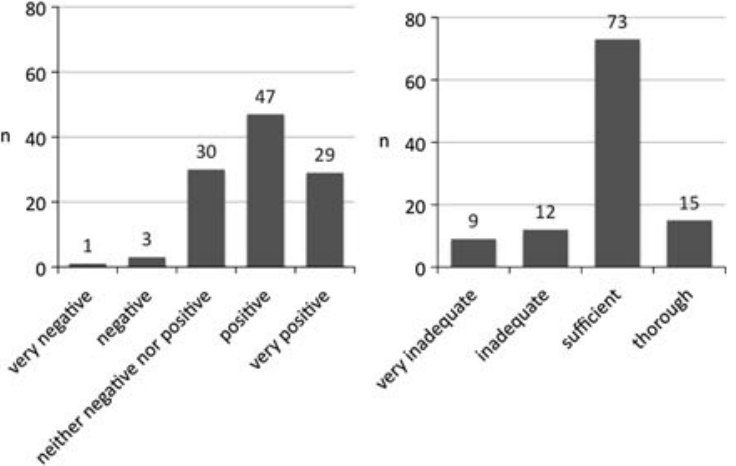

The preoccupation factor correlated with the HADS-A domain $\left(r_{\mathrm{s}}=-0.47, p<0.001\right)$, and the SF-36 domains mental health (MH, $\left.r_{\mathrm{s}}=0.73, p<0.001\right)$ and vitality (VT, $\left.r_{\mathrm{s}}=-0.53, p<0.001\right)$. Significant differences were seen between probable cases of anxiety and non-cases (HADS-A $>10$ vs. $<8$ ) regarding AIIQ items addressing preoccupation (items 1, 2, 4 and 5, $p=0.002-0.009$ ), with probable cases scoring 0.61-0.85 units lower than non-cases. They also reported a greater impact on HRQL during follow-up (item 6, $p=0.006$ ). However, no differences were seen regarding worry associated with the termination of the programme (item 3). Significant differences were also seen between probable cases of depression and non-cases (HADS-D $>10 \mathrm{vs}$. $<8$ ) regarding impact on everyday life (item $4, p=0.004$ ), thoughts about the AI during the last month (item 5, $p=0.001$ ), and general assessment of the programme after termination (item $7, p=0.02$ ), with probable cases of depression scoring $0.55-0.86$ units lower than non-cases.

Relationships between patient and tumour characteristics and health-related quality of life

Patient age was negatively correlated with the SF-36 domain physical functioning (PF, $r_{\mathrm{s}}=-0.34, p<0.0003$ ).

Table 2 The adrenal incidentaloma impact questionnaire-exploratory factor analysis

\begin{tabular}{lcc}
\hline & \multicolumn{2}{l}{ Factor } \\
\cline { 2 - 3 } AIIQ & Preoccupation & Evaluation \\
\hline Item 1 & 0.843 & -0.049 \\
Item 2 & 0.863 & -0.092 \\
Item 3 & -0.268 & 0.755 \\
Item 4 & 0.683 & 0.375 \\
Item 5 & 0.761 & 0.322 \\
Item 6 & 0.267 & 0.577 \\
Item 7 & 0.107 & 0.762 \\
Item 8 & 0.152 & 0.679 \\
\hline
\end{tabular}

Factor loadings in the final model 


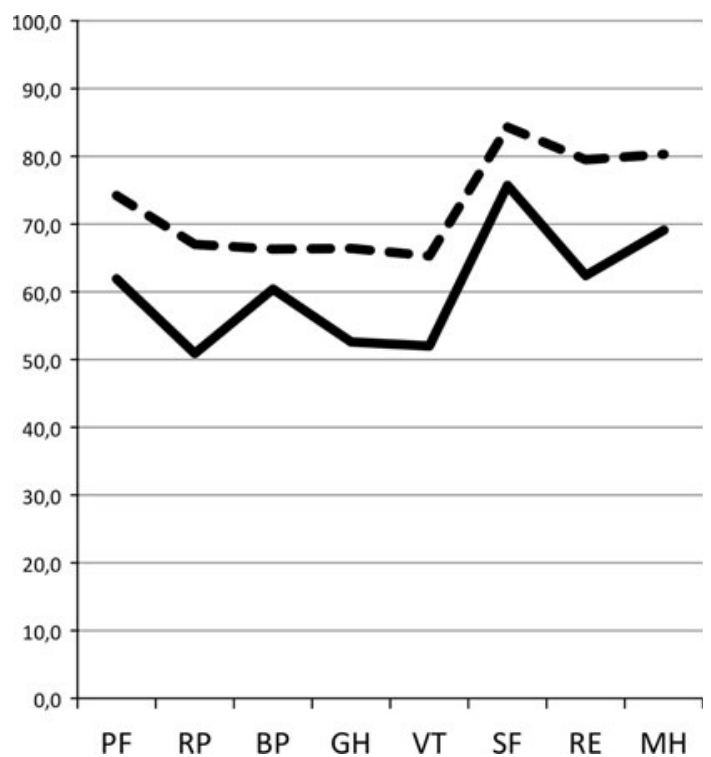

Fig. 2 The short form-36-results for respondents versus age and gender-matched norms legend: means for individual domains for the respondents (solid line) and an age and sex-matched reference sample drawn from the Swedish norm database (hatched line). Differences were statistically significant in all domains $(p=0.00004-0.009)$, except BP $(p=0.085)$. $P F$ physical functioning, $R P$ role physical, $B P$ bodily pain, $G H$ general health, $V T$ vitality, $S F$ social functioning, $R E$ role emotional, $M H$ mental health

Co-morbidity index also correlated with several domains of SF-36. Weaker, statistically not significant, associations were seen between co-morbidity and HADS-A $\left(r_{\mathrm{s}}=0.18\right.$, $p=0.06)$, and HADS-D $\left(r_{\mathrm{s}}=0.18, p=0.06\right)$. No correlations were seen between HRQL and sex, tumour size, location (uni- or bilateral), UFC or $1 \mathrm{mg}$-DST cortisol levels, with the exception of UFC, where higher UFC levels correlated with better scoring on the SF-36 domain social functioning (SF, $r_{\mathrm{s}}=0.21, p=0.04$ ) (Table 3). No significant differences were seen between HADS non-cases, possible and probable cases with regard to UFC or $1 \mathrm{mg}$-DST cortisol levels.

\section{Discussion}

This study of patient-reported outcomes after completion of a 2-year follow-up programme for an incidentally discovered adrenal lesion without proven abnormal hormone production or malignancy suggests that the AI follow-up programme was well tolerated. Only $4 \%$ experienced the follow-up programme as negative, and only $2 \%$ reported increased worry after completing the programme. However, nearly $30 \%$ were identified as having possible or probable anxiety or depression, and these patients also had a more negative experience of the programme.

We identified patients from a follow-up study in western Sweden [6, 7], in which all patients with AI detected at all radiology departments in our region (population 1.7 million) during an 18-month period were enrolled. The dropout rate during follow-up was low [6], and the present cohort may be regarded as representative for unselected patients diagnosed with $\mathrm{AI}$ in our region. The present study is, to our knowledge, the first that has attempted to directly assess patient reported outcomes of a follow-up programme in a large prospective, population-based series of conservatively managed AI patients. Owecki et al. [20] found increased anxiety levels and mild depression in a study of 26 polish patients with AI [20]. Brunaud et al. [21] measured the impact on HRQL of living with an AI using proxy surgeons' ratings [21]. Kastelan et al. [22] recently reported on the HRQL of AI patients seen at a referral centre compared to an age and sex-matched control group.

In our study, $29 \%$ of the respondents were identified as possible or probable cases of anxiety (HADS-A $\geq 8$ ), and $30 \%$ had possible or probable depression (HADS-D $\geq 8$ ). Corresponding figures have been reported for patients with chronic diseases, such as coronary heart disease (HADS-A: 30-38 \%, HADS-D: 15-50 \%) [23-25]; diabetes type 2 (HADS-A: $20 \%$ ) [26]; chronic obstructive pulmonary disease (HADS-A: $27 \%$, HADS-D: $14 \%$ ) [27]; Parkinson's disease (HADS-A: $44 \%$, HADS-D: $30 \%$ ) [28]; and after curative treatment for head and neck cancer (HADSA: 16-28 \%, HADS-D: 9-17 \%) [29, 30].

Patients with AI are diagnosed as a consequence of work-up for an unrelated problem, and our study population has a high prevalence of co-existing morbidity (Table 1). Using a crude co-morbidity index there was a clear correlation between co-morbidity and worse HRQL in all physical domains of SF-36 as well as role emotional. Respondents also scored lower on nearly all domains of SF36 , reflecting a generally worse HRQL, compared with age and sex-matched norms from the general population. This is in agreement with the findings of Kastelan et al. [22].

Patients with probable anxiety (HADS-A $>10$ ) reported a greater impact on their HRQL during follow-up, but were not significantly more worried about the termination of the programme than were non-cases. The potential effect of subclinical hormone overproduction, e.g. subclinical hypercortisolism, is an intriguing issue [19]. However, in the present study UFC and $1 \mathrm{mg}$-DST cortisol levels, adrenal lesion size or bilaterality did not correlate significantly with any of the domains of AIIQ, HADS or SF-36. The only exception was the correlation between UFC levels and the SF-36 domain Social Function, where higher UFC levels were significantly associated with better Social Function, most likely a spurious correlation. HADS-A and HADS-D had a stronger, although not statistically significant $(p=0.06)$, relationship with co-morbidity index. This suggests that comorbidity, rather than a direct effect of the AI or the follow-up programme as such, was the main explanation for the levels of anxiety and depression seen in this 
Table 3 Correlation analysis between patient and tumour characteristics and HRQL

\begin{tabular}{|c|c|c|c|c|c|c|c|}
\hline & Sex & Age & $\begin{array}{l}\text { Comorbidity } \\
\text { index }\end{array}$ & Uni/bilateral & Size & UFC & $1 \mathrm{mg}-\mathrm{DST}$ \\
\hline \multicolumn{8}{|l|}{ AIIQ } \\
\hline Preoccupation & $0.083(0.39)$ & $0.036(0.71)$ & $-0.104(0.28)$ & $0.044(0.65)$ & $-0.037(0.70)$ & $-0.071(0.49)$ & $0.16(0.15)$ \\
\hline Evaluation & $-0.002(0.98)$ & $0.049(0.62)$ & $0.013(0.89)$ & $-0.018(0.85)$ & $-0.081(0.40)$ & $-0.015(0.88)$ & $-0.12(0.26)$ \\
\hline \multicolumn{8}{|l|}{ HADS } \\
\hline Anxiety & $-0.066(0.49)$ & $-0.30(0.76)$ & $0.181(0.062)$ & $0.098(0.31)$ & $0.035(0.72)$ & $-0.13(0.22)$ & $-0.12(0.29)$ \\
\hline Depression & $0.005(0.96)$ & $0.042(0.67)$ & $0.178(0.065)$ & $0.16(0.099)$ & $-0.082(0.40)$ & $-0.12(0.24)$ & $0.032(0.79)$ \\
\hline \multicolumn{8}{|l|}{ Short form-36 } \\
\hline $\begin{array}{l}\text { Physical } \\
\text { functioning }\end{array}$ & $0.147(0.13)$ & $-0.335(0.0003)^{*}$ & $-0.245(0.010)^{*}$ & $-0.073(0.45)$ & $-0.075(0.44)$ & $-0.031(0.76)$ & $-0.035(0.75)$ \\
\hline Role physical & $0.049(0.612)$ & $-0.166(0.086)$ & $-0.275(0.004)^{*}$ & $-0.011(0.91)$ & $-0.078(0.42)$ & $0.069(0.50)$ & $0.044(0.70)$ \\
\hline Bodily pain & $0.15(0.12)$ & $-0.064(0.51)$ & $-0.219(0.023)^{*}$ & $-0.16(0.11)$ & $-0.103(0.28)$ & $0.005(0.96)$ & $0.026(0.82)$ \\
\hline General health & $0.095(0.32)$ & $-0.056(0.56)$ & $0.323(0.001)^{*}$ & $-0.12(0.23)$ & $-0.059(0.54)$ & $0.073(0.47)$ & $-0.095(0.39)$ \\
\hline Vitality & $0.061(0.53)$ & $-0.036)(0.71)$ & $-0.105(0.28)$ & $-0.182(0.058)$ & $-0.027(0.78)$ & $0.037(0.72)$ & $0.051(0.65)$ \\
\hline $\begin{array}{l}\text { Social } \\
\text { functioning }\end{array}$ & $0.035(0.72)$ & $-0.060(0.53)$ & $-0.108(0.27)$ & $-0.11(0.24)$ & $-0.009(0.93)$ & $0.213(0.035)^{*}$ & $-0.082(0.46)$ \\
\hline $\begin{array}{l}\text { Role } \\
\text { emotional }\end{array}$ & $0.15(0.12)$ & $-0.134(0.16)$ & $-0.216(0.025)^{*}$ & $-0.007(0.95)$ & $0.021(0.83)$ & $0.15(0.15)$ & $-0.060(0.59)$ \\
\hline Mental health & $0.098(0.31)$ & $-0.022(0.82)$ & $-0.092(0.34)$ & $-0.166(0.086)$ & $0.044(0.65)$ & $0.13(0.21)$ & $0.003(0.98)$ \\
\hline
\end{tabular}

Data presented as Spearman's rho ( $p$ value), $* p<0.05$

patient group. In fact, only four respondents $(4 \%)$ rated their experience of the programme as negative. Still, the patientreported measurements of the impact over time of the AI are retrospective and may be prone to recall bias, and definite conclusions about cause and effect cannot be drawn. Prospective studies are needed to study possible associations of anxiety and depression with tolerance to follow-up algorithms for AI.

Personalised and adequate patient information in a follow-up setting after a pathological test result has been shown to reduce anxiety [31]. We saw that a negative assessment of the given information significantly correlated with greater preoccupation with the AI after the programme. This is in line with the findings of Bell et al. [32], in a study of psychological adjustment to cervical screening, that patients reporting a high degree of initial worry at the abnormal test result were more likely to perceive the information they were given as inadequate and showed more concern at the time of the interview. Recently, Van Esch et al. [33] reported that the personality trait neuroticism and symptoms of depression and anxiety prior to a diagnosis of breast cancer were the most important predictors of HRQL 1 and 2 years after surgery. In a general setting, the perception of risk and worry are only weakly correlated [34], and patient-associated factors such as educational level [35, 36], living in urban or rural areas [36], number of children [36], and individual coping strategies [37] all correlate with psychological impacts. Still, focused counselling resources to patients with a high degree of anxiety at detection of AI may prevent unnecessary adrenalectomies and decrease negative impacts of follow-up.

Our study has limitations. Assessments were made only after completion of the follow-up programme. Hence, answers are retrospective in nature and no definite inferences regarding causality may be made. Due to the lack of appropriate instruments the AIIQ was specifically developed for this study. Although the AIIQ showed good face validity and construct validity (correlation between the preoccupation factor and HADS-A), the instrument needs to be further evaluated. Unfortunately, the Swedish normative database [15] did not allow matching for co-morbidities in the SF-36 comparison. Sociodemographic information was not collected, as it was felt that it might have reduced the response rate, thus further analyses by potentially relevant variables were precluded.

In summary, almost all patients in this cohort with incidentally discovered adrenal lesions reported satisfaction with the follow-up programme and were relieved or unconcerned when follow-up was ended. Although most were worried when the AI was detected, only a few remained worried during follow-up, and for these tailored counselling is suggested as a means to decrease negative impacts of follow-up. Overall, a 2-year follow-up programme for incidentally discovered adrenal lesions was well tolerated. 
Acknowledgments The authors wish to thank Dr. Erik Almqvist, MD, PhD; Dr. Stefan Ander, MD, PhD; Dr. Sture Carlsson, MD; Dr. Eva Ekerstad, MD; Dr. Galina Götherström, MD, PhD; Dr. Carina Forsberg, MD; Dr. Helga Á Sigurjonsdottir, MD, PhD; and Dr. Håkan Widell, MD for their valuable input on the Adrenal Incidentaloma Impact Questionnaire. The authors also thank Nils-Gunnar Pehrsson for his valuable statistical advice. This study was supported by grants from the Swedish Cancer Society; The Västra Götaland Region Research Funding supported this study under the LUA/ALF agreement: The Västra Götaland Region Research Fund; and The Göteborg Medical Society.

Conflict of interest There is no conflict of interest that could be perceived as prejudicing the impartiality of the research reported.

Open Access This article is distributed under the terms of the Creative Commons Attribution License which permits any use, distribution, and reproduction in any medium, provided the original author(s) and the source are credited.

\section{References}

1. M.F. Herrera, C.S. Grant, J.A. van Heerden, P.F. Sheedy, D.M. Ilstrup, Incidentally discovered adrenal tumors: an institutional perspective. Surgery 110(6), 1014-1021 (1991)

2. F. Mantero, M. Terzolo, G. Arnaldi, G. Osella, A.M. Masini, A. Ali, M. Giovagnetti, G. Opocher, A. Angeli, A survey on adrenal incidentaloma in Italy. Study Group on Adrenal Tumors of the Italian Society of Endocrinology. J. Clin. Endocrinol. Metab. 85(2), 637-644 (2000)

3. B. Bulow, B. Ahren, Adrenal incidentaloma-experience of a standardized diagnostic programme in the Swedish prospective study. J. Intern. Med. 252(3), 239-246 (2002)

4. B. Bulow, S. Jansson, C. Juhlin, L. Steen, M. Thoren, H. Wahrenberg, S. Valdemarsson, B. Wangberg, B. Ahren, Adrenal incidentalomafollow-up results from a Swedish prospective study. Eur. J. Endocrinol. 154(3), 419-423 (2006)

5. A.A. Kasperlik-Zaluska, M. Otto, A. Cichocki, E. Roslonowska, J. Slowinska-Srzednicka, W. Jeske, L. Papierska, W. Zgliczynski, Incidentally discovered adrenal tumors: a lesson from observation of 1,444 patients. Horm. Metab. Res. 40(5), 338-341 (2008)

6. A. Muth, L. Hammarstedt, M. Hellstrom, H.A. Sigurjonsdottir, E. Almqvist, B. Wangberg, Cohort study of patients with adrenal lesions discovered incidentally. Br. J. Surg. 98(10), 1383-1391 (2011)

7. L. Hammarstedt, A. Muth, B. Wangberg, L. Bjorneld, H.A. Sigurjonsdottir, G. Gotherstrom, E. Almqvist, H. Widell, S. Carlsson, S. Ander, M. Hellstrom, Adrenal lesion frequency: a prospective, cross-sectional CT study in a defined region, including systematic re-evaluation. Acta Radiol. 25, 25 (2010)

8. R.T. Kloos, M.D. Gross, I.R. Francis, M. Korobkin, B. Shapiro, Incidentally discovered adrenal masses. Endocr. Rev. 16(4), 460-484 (1995)

9. W.F. Young Jr, Clinical practice. The incidentally discovered adrenal mass. N. Engl. J. Med. 356(6), 601-610 (2007)

10. T.J. Cawood, P.J. Hunt, D. O'Shea, D. Cole, S. Soule, Recommended evaluation of adrenal incidentalomas is costly, has high false-positive rates and confers a risk of fatal cancer that is similar to the risk of the adrenal lesion becoming malignant; time for a rethink? Eur. J. Endocrinol. 161(4), 513-527 (2009)

11. NIH state-of-the-science statement on management of the clinically inapparent adrenal mass (incidentaloma). NIH Consens State Sci Statements 19, 1-25 (2002)
12. N. Valli, B. Catargi, N. Ronci, V. Vergnot, F. Leccia, J.M. Ferriere, G. Chene, N. Grenier, F. Laurent, A. Tabarin, Biochemical screening for subclinical cortisol-secreting adenomas amongst adrenal incidentalomas. Eur. J. Endocrinol. 144(4), 401-408 (2001)

13. M.A. Zeiger, G.B. Thompson, Q.Y. Duh, A.H. Hamrahian, P. Angelos, D. Elaraj, E. Fishman, J. Kharlip, The American Association of Clinical Endocrinologists and American Association of Endocrine Surgeons medical guidelines for the management of adrenal incidentalomas. Endocr. Pract. 15(Suppl 1), 1-20 (2009)

14. G.W. Boland, M.A. Blake, P.F. Hahn, W.W. Mayo-Smith, Incidental adrenal lesions: principles, techniques, and algorithms for imaging characterization. Radiology 249(3), 756-775 (2008)

15. M. Sullivan, J. Karlsson, C. Taft, SF-36 Hälsoenkät: Svensk Manual och Tolkningsguide, vol. 2 (Sahlgrenska University Hospital, Göteborg, 2002)

16. A.S. Zigmond, R.P. Snaith, The hospital anxiety and depression scale. Acta Psychiatr. Scand. 67(6), 361-370 (1983)

17. I. Bjelland, A.A. Dahl, T.T. Haug, D. Neckelmann, The validity of the Hospital Anxiety and Depression Scale. An updated literature review. J. Psychosom. Res. 52(2), 69-77 (2002)

18. L.K. Nieman, B.M. Biller, J.W. Findling, J. Newell-Price, M.O. Savage, P.M. Stewart, V.M. Montori, The diagnosis of Cushing's syndrome: an endocrine society clinical practice guideline. J. Clin. Endocrinol. Metab. 93(5), 1526-1540 (2008)

19. I. Chiodini, Clinical review: diagnosis and treatment of subclinical hypercortisolism. J. Clin. Endocrinol. Metab. 96(5), 1223-1236 (2011)

20. M. Owecki, I. Warmuz-Stangierska, K.A. Majewska, E. Nikisch, J. Sowinski, Depression and anxiety in patients with adrenal tumor incidentally found on abdominal imaging performed for other indications. Pol Merkur Lekarski 19(110), 166-168 (2005)

21. L. Brunaud, E. Kebebew, F. Sebag, R. Zarnegar, O.H. Clark, Q.Y. Duh, Observation or laparoscopic adrenalectomy for adrenal incidentaloma? A surgical decision analysis. Med Sci Monit 12(9), CR355-CR362 (2006)

22. D. Kastelan, F. Dzubur, T. Dusek, T. Poljicanin, Z. Crncevic-Orlic, I. Kraljevic, M. Solak, T. Bencevic, I. Aganovic, N. Knezevic, Z. Kastelan, M. Korsic, Health-related quality of life and fatigue in patients with adrenal incidentaloma. Endocrine 40, 84-89 (2011)

23. C.R. Martin, R.J. Lewin, D.R. Thompson, A confirmatory factor analysis of the Hospital Anxiety and Depression Scale in coronary care patients following acute myocardial infarction. Psychiatr. Res. 120(1), 85-94 (2003)

24. C.R. Martin, D.R. Thompson, D.S. Chan, An examination of the psychometric properties of the Hospital Anxiety and Depression Scale in Chinese patients with acute coronary syndrome. Psychiatr. Res. 129(3), 279-288 (2004)

25. J. Barth, C.R. Martin, Factor structure of the Hospital Anxiety and Depression Scale (HADS) in German coronary heart disease patients. Health Qual Life Outcomes 3(15), 15 (2005)

26. V. Bouwman, M.C. Adriaanse, E. van 't Riet, F.J. Snoek, J.M. Dekker, G. Nijpels, Depression, anxiety and glucose metabolism in the general Dutch population: the new Hoorn study. PLoS One 5(4), e9971 (2010)

27. E. Balcells, J. Gea, J. Ferrer, I. Serra, M. Orozco-Levi, J. de Batlle, E. Rodriguez, M. Benet, D. Donaire-Gonzalez, J.M. Anto, J. Garcia-Aymerich, Factors affecting the relationship between psychological status and quality of life in COPD patients. Health Qual Life Outcomes 8(108), 108 (2010)

28. C. Rodriguez-Blazquez, B. Frades-Payo, M.J. Forjaz, J. de PedroCuesta, P. Martinez-Martin, Psychometric attributes of the Hospital Anxiety and Depression Scale in Parkinson's disease. Mov. Disord. 24(4), 519-525 (2009)

29. E. Hammerlid, E. Silander, L. Hornestam, M. Sullivan, Healthrelated quality of life 3 years after diagnosis of head and neck cancer-a longitudinal study. Head Neck 23(2), 113-125 (2001) 
30. I.M. Verdonck-de Leeuw, W.J. van Bleek, C.R. Leemans, R. de Bree, Employment and return to work in head and neck cancer survivors. Oral Oncol. 46(1), 56-60 (2010)

31. C. Wilkinson, J.M. Jones, J. McBride, Anxiety caused by abnormal result of cervical smear test: a controlled trial. BMJ 300(6722), 440 (1990)

32. S. Bell, M. Porter, H. Kitchener, C. Fraser, P. Fisher, E. Mann, Psychological response to cervical screening. Prev. Med. 24(6), 610-616 (1995)

33. L. Van Esch, J.A. Roukema, M.F. Ernst, G.A. Nieuwenhuijzen, J. De Vries, Combined anxiety and depressive symptoms before diagnosis of breast cancer. J. Affect. Disord. 136(3), 895-901 (2012)
34. L. Sjoberg, Worry and risk perception. Risk Anal. 18(1), 85-93 (1998)

35. E. Lindholm, B. Berglund, J. Kewenter, E. Haglind, Worry associated with screening for colorectal carcinomas. Scand. J. Gastroenterol. 32(3), 238-245 (1997)

36. P. Olsson, K. Armelius, G. Nordahl, P. Lenner, G. Westman, Women with false positive screening mammograms: How do they cope? J. Med. Screen. 6(2), 89-93 (1999)

37. A. Miles, J. Wardle, Adverse psychological outcomes in colorectal cancer screening: Does health anxiety play a role? Behav. Res. Ther. 44(8), 1117-1127 (2006) 